\title{
RELIGIÃO E PSICOLOGIA NO AZUL DA CONGREGAÇÃO DA IMACULADA CONCEIÇÃO DE CASTRES
}

\author{
RELIGION AND PSYCHOLOGY IN THE BLUE OF THE CONGREGATION OF THE \\ IMMACULATE CONCEPTION OF CASTRES
}

Juliana Neri Munhoz ${ }^{1}$

RESUMO: Algumas questões que envolvem a religião são discutidas pelo viés da Psicologia da Religião pensando na influência da religião e da religiosidade na saúde do indivíduo, observando assim alguns traços positivos e negativos sobre sua saúde mental. Nos estudos e pesquisas sobre as relações entre práticas religiosas e saúde psicológica encontramos um elemento importante presente nestes grupos religiosos que seria a figura do líder religioso.Alguns quadros psicológicos encontrados nestes líderes podem se relacionar a algumas condições individuais ou religiosas impostas. Neste aspecto este artigo irá relacionar estudos já feitos com as experiências de algumas freiras da Congregação das Irmãs Azuisde 1836 a 1844 na França.

Palavras-chave:Psicologia- Congregação religiosa católica- líderes religiosos

ABSTRACT: Some issues involving religion are discussed by the bias of the Psychology of Religion thinking about the influence of religion and religiosity on the individual's health, thus observing some positive and negative traits about their mental health. In studies and research on the relationship between religious practices and psychological health we find an important element present in these religious groups that would be the figure of the religious leader. Some psychological frameworks found in these leaders may relate to some imposed individual or religious conditions. In this aspect his article will relate studies already done with the experiences of some nuns of the Congregation of the Blue Sisters in 1836 to 1844 in France.

Keywords: Psychology - Catholic religious congregation; religious leaders

\section{Os líderes religiosos e saúde mental}

Nas pesquisas sobre transtornos mentais em ministros e líderes religiosos feito por Neto, Lotufo,Martins(2009) mostra-se como alguns quadros psicológicos encontrados nestes líderes podem se relacionar a algumas condições individuais ou religiosas impostas e colocadas a estes padres e freiras. Os autores trouxeram exemplos de religiosos e religiosas que tenham tido experiências psicopatológicas e foram internados e internadas e estavam sobre tratamento psicológico. Desta forma, compreendendo a importância dos líderes

\footnotetext{
${ }^{1}$ Doutoranda em Ciência da Religião pela PUC-SP. Mestre e especialista em Ciência da Religião- PUC SP. Graduada em Ciências Sociais pela Unesp.
} 
religiosos e as experiências religiosas citadas nas memórias da Congregação da Imaculada Conceição de Castres- Irmãs Azuis- fundada na cidade de Castres na França por Emilie de Villeneuve em 1836, vamos observar como algumas freiras que entraram e saíram da Congregação podem ter algumas características psicológicas relevantes para análise, fazendo sempre uma associação e comparação aos estudos já realizados pela Psicologia da Religião.

Pensando no trabalho de um líder religioso, como lembra Silva (2004) a religião pode ser considerada como criadora de soluções para problemas da realidade construída socialmente. No trabalho destes e destas, as construções do significado e da identidade social também podem transformar a vida individual (até psicologicamente falando) e social. Ou seja, como no trabalho destes líderes religiosos lida-se com o sofrimento em suas atividades cotidianas e como este tipo de trabalho lida com questões que o diferenciam de outros como sua vocação, seu perfil e a moral que o envolve.

Como coloca Weber, no líder religioso a prova de seu carisma se dá a partir do poder de influenciar outras pessoas a seguirem suas ideias e assim se sentirem bem. A manutenção da imagem que é construída em torno deste líder é fundamental. Torna-se um exemplo e a sua figura são atribuídas ações e condutas sobrenaturais. A manutenção dessa imagem impõe restrições e regras de conduta. O trabalho pastoral, dessa forma, não se assemelha ao de um engenheiro ou médico, mas se diferencia por seu caráter ascético, espiritual e ético (WEBER, 1982).

Esta manutenção da imagem religiosa, restrições, problemas de relacionamento, falta de apoio, adaptação a situações difíceis, cobranças, etc podem causar assim como em qualquer outra função profissional stress e questões que afetam a saúde mental do líder religioso. Podemos buscar em algumas pesquisas feitas por Neto, Lotufo, Martins:

A experiência religiosa é única, diferente das vivências do dia a dia, afeta as percepções centrais sobre si próprio e sobre a vida, pode mudar as noções sobre quem você é e o sentido ou significado da sua vida. A experiência religiosa é complexa do ponto de vista psicológico, envolvendo emoções, crenças, atitudes, valores, comportamentos, e ambiente social. Ela transcende estas categorias psicológicas e dá ao indivíduo um sentido de integridade. NETO, LOTUFO, MARTINS (2009, p.13)

As percepções que o líder religioso pode ter de si e as emoções que o envolvem ligadas a sua religião intrínseca, ou seja, em que sua motivação principal para a vida é a religião faz com que outras necessidades, por mais fortes que sejam, passem a serem vistas como secundárias e são, dentro do possível, harmonizadas com as crenças e prescrições religiosas. Mas até que ponto essas outras necessidades não causam no indivíduo, se não harmonizadas, problemas psicológicos? 
Dalgalarrondo (2008) relata em seu livro Religião, Psicopatologia e Saúde mental que apesar de a maioria das evidências empíricas apontar para uma associação positiva entre saúde mental, religião e religiosidade alguns aspectos negativos são identificados por algumas pesquisas como culpa excessiva, perfeccionismo, pensamentos obsessivos, ansiedade. Como coloca o autor, a religião disfuncional é muito negativa e procura o controle social através da culpa, medo e vergonha. Muitas pessoas sentem grande apoio e orientação, segurança e clareza neste ambiente, pois não precisam tomar decisões morais, apenas seguir a "linha do partido" com fé e confiança.

Como observaram os autores Neto, Lotufo, Martins (2009) as implicaçõesda religião quanto à conduta são claras em algumas orientações, e obscuras em outras. Por exemplo, as recompensas e responsabilidades esperadas, as atitudes e valores individuais, efeitos da educação, subscrição a padrões morais e éticos. Dessa forma, algumas questões negativas nessa compreensão da religião podem interferir no trabalho e trajetória religiosa destes religiosos e religiosas.

Neste artigo busca-se associar questões detranstornos mentaise a questão da anormalidadepresente em alguns líderes religiosos. Agora, como lembra Neto, Lotufo, Martins (2009) o que é a normalidade e o que poderíamos considerar anormal no comportamento destes líderes religiosos?

\begin{abstract}
Normal, de uma maneira geral, é aquilo que está de acordo com determinadas normas, regras ou padrões. Esse acordo não significa identidade absoluta. Se, com relação a peças de maquinaria e outros objetos inanimados, pode-se exigir que sejam rigorosamente iguais para que satisfaçam os padrões de qualidade, o mesmo não se dá com criaturas mais complexas como são os seres vivos. Os padrões, neste caso, são elásticos, dando margem a certa diversidade, o que é particularmente verdadeiro com relação ao homem (NETO, LOTUFO, MARTINS 2009, p.23)
\end{abstract}

Como coloca o autor, isso mostra a dificuldade de se conceituar a normalidade e o quanto são incompletas as definições. De qualquer forma, pode-se deixar de lado as conceituações de "normal”, mais vamos procurar descrever as características da saúde mental. Pensando na denominada normalidade como algo elástico, ou seja, que pode variar devido à complexidade humana, vamos relacionar a normalidade com a saúde mentale alguns elementos que podem ser considerados: a auto estima e o respeito próprio:

Temos reparado, por outro lado, que uma diminuição da autoestima manifesta-se, frequentemente pela preocupação de comparar-se com as demais pessoas; logo no primeiro contato, muitas pessoas tendem a ficar refletindo se serão "inferiores" ou "superiores" aos seus interlocutores. Das conclusões a que chegarem, vai depender a maneira de tratá-los. Ora, o indivíduo que tem uma imagem de si mesmo estável e positiva reconhece que é diferente dos demais, mas não se julga nem pior nem melhor do que ninguém, no cômputo geral de qualidades e defeitos. É interessante notar que a "regra áurea" do cristianismo não recomenda que amemos o próximo 
mais ou menos, mas tanto quanto a nós mesmos. NETO, LOTUFO, MARTINS (2009, p.30.)

Pensando nos ideais do Cristianismo e no seguimento das normas cristãs, aparentemente a religião é um elemento que possibilita uma saúde mental se o indivíduo leva em conta esse amor que recebe de Deus e que ame a si mesmo e ao próximo. Os problemas de transtornos ou ditas anormalidades encontradas em especial nas freiras e padres que buscam se dedicar a esses princípios precisam ser estudados em suas particularidades, associando ao trabalho e ao cargo de líder religioso. A relação do trabalho religioso e o religioso pode envolver desejos, vivência de prazer e sofrimento. Como cita Silva (2004) a resignação, o desencorajamento, o desânimo e a frustração podem não ser resultantes de uma patologia, mas pode envolver também a realidade do sujeito com o trabalho religioso. Alguns exemplos de líderes religiosos e até iniciantes com transtornos psicológicos podem ser associados a estas questões.

Alguns autores como Larson em algumas pesquisas apresentadas por Neto, Lotufo, Martins (2009) percebem duas variáveis: o compromisso religioso foi benéfico à saúde mental, principalmente quando a religião dá apoio social, a prática religiosa o faz se sentir bem e a experiência de relacionamento com Deus é mais forte. Quando a religião não é bem definida para o indivíduo ou se referem apenas à importância do significado que a experiência religiosa provê, o resultado pode ser negativo. Interessante notar que a maioria dos profissionais de saúde mental considera que o papel da religião é o de oferecer significado para vida. Mais não é só isso, é preciso o estabelecimento de um laço mais forte com a religião. Pode ocorrer de diferentes formas o entendimento de como o compromisso religioso é relevante ou considerado um elemento fundamental para a vida do líder religioso: ou de um peso, um fardo ou algo que o estimula a entrar em contato com a comunidade religiosa e que faz parte da sua realização pessoal, trazendo benefícios como auto estima, tranquilidade e liberdade de expressar o que podemos chamar de vocação.

$\mathrm{Na}$ vida religiosa o trabalho religioso e a dedicação as atividades religiosas em especial em Congregações religiosas, exige tempo para fazer todas as coisas, não apenas em termos diários, mas também semanais, mensais, semestrais, etc. Isso pode gerar situações estressantes como coloca Siqueira (2014), e as variáveis como crenças a respeito de si, do mundo e do futuro, bem como pensamentos e o controle de uma situação estressante estão relacionados e influenciam a compreensão de um estímulo como algo ameaçador ou não. $\mathrm{Ou}$ seja, a forma como a pessoa está vulnerável a algum acontecimento e acredita poder superar 
barreiras de uma determinada situação. No caso do líder religioso ou religiosa as situações e obrigações podem gerar isso.

Como diz Silva (2004) em qualquer trabalho, na esteira da produção fabril, é preciso estar alerta ao tempo para dar conta de toda a produção, pois se não dá conta, pune-se de alguma forma. Enxergar o sofrimento como um desafio a ser superado é também outra forma de enfrentar o sofrimento gerado. Se não for assim, por exemplo, muitos não conseguem dar continuidade na sua trajetória religiosa como líderes religiosas, pois o sofrimento encontrado na abstenção das vontades e ambições materiais (como é posto pela Congregação Imaculada Conceição de Castres) seria maior do que o indivíduo consegue aguentar.

\section{Memórias das Irmãs Azuis e a Psicologia da Religião}

No capítulo em que os autores Neto, Lotufo, Martins (2009) discutem sobre transtornos mentais em ministros e líderes religiosos mostra-se como alguns quadros psicológicos encontrados nestes líderes podem se relacionar a algumas condições individuais ou religiosas impostas e colocadas a estes padres e freiras. Buscam-se exemplos de religiosos e religiosas que tenham tido experiências psicopatológicas e foram internados e internadas e estavam sobre tratamento psicológico.Os autores trazem elementos importantes como o papel social valioso do líder, a capacidade deste líder em utilizar sua experiência de vida, de organização e como são aceitos em épocas adequadas e propícias a isso. Emilie de Villeneuve, naquele contexto francês sendo de família nobre, teve contato com padres, bispos que de alguma forma colocavam a necessidade, em um primeiro momento que ela fosse fundadora de uma obra religiosa- A Congregação da Imaculada Conceição de Castres. E esta, pelas suas vontades, seria uma irmã de caridade e não uma fundadora. O pai de Emilie adiantou sobre o dote de sua filha a quantia para comprar, no centro da cidade de Castres uma casa simples (pela exigência da filha) com alguns móveis antigos do castelo e um valor era dado para filha mensalmente. Desta forma, foi possível Emilie e mais duas companheiras fundarem a Congregação das Irmãs Azuis inicialmente com uma oficina de costura para jovens. E conforme o número de jovens ia aumentando, buscam apoio para irem para um local maior.

Podemos nos remeter inicialmente as próprias ações da fundadora e o processo de adaptação a uma nova realidade com as novas integrantes da Congregação. Como as irmãs que estão se preparando e iniciando em uma Congregação religiosa podem ter diferentes formas de compreensão desta mudança de vida e adaptação a uma função religiosa? O 
período que observamos alguns exemplos disto na Congregação da Imaculada Conceição de Castres se dá entre 1836-1844 na cidade de Castres na França.

No início da Congregação da Imaculada Conceição de Castres com a fundadora Emilie de Villeneuve na França em 1836, várias situações de dificuldade foram encontradas através de cartas e de memórias registradas. Muitas falas, comentários e entrada e saída de noviças merecem ser vistas com um olhar da Psicologia da Religião. É necessário um cuidado metodológico, partindo do pressuposto de que várias são as experiências e particularidades das irmãs azuis: ano, cidade, origem destas irmãs, questões familiares e pessoais, dentre outras. O que é possível perceber e trazer para discussão são as possíveis influências e problemas que enquanto freiras é possível analisar. Compreendendo a importância dos líderes religiosos e as experiências religiosas citadas nas memórias da Congregação é importante observarrelatos que se remetem a problemas e transtornos psicológicos.

Tendo como base exemplos como o trabalho de Paulo Dalgalarrondo (2008) que é um estudo com coleta de dados sobre quadros agudos e transtornos mentais em clérigos e ministros religiosos internados com situações de esquizofrenia, melancolia, depressão, psicose e além de uma comparação dos números destes diagnósticos entre sacerdotes, leigos, freiras em clausura. É interessante perceber nas pesquisas citadas e através dos dados, como questões de dúvidas sobre a vocação, sentimento de falta de estabilidade e segurança, dificuldades de adaptação, estresse, depressão, são elementos que aparecem como transtornos para freiras e sacerdotes. Em alguns relatos nas Memórias da Congregação das Irmãs Azuis encontramos algumas situações:

Uma jovem chamada Zoé, no início da Congregação das Irmãs Azuis, em uma noite de inverno, ficou junto de um poço para rezar de 2 a 4 horas sobre o gelo. Teve problemas de saúde e não foi aceita pela Congregação teve reações de gritar se jogando na cama de uma das internas e ela foi vigiada durante a noite pelo medo de que se suicidasse. Chamaram-na de pobre louca que não comeu nada nesses três dias até outro responsável buscá-la.Neste caso a influência negativa da religião se deu pela compreensão de elementos que fazem parte dos votos e preparação das religiosas através da anulação de desejos e sacrifícios associados as penitências e ao medo de não ser aceita pela Congregação.

Um dos casos de algumas internas como se contam no site das Memórias da Congregação da Imaculada Conceição de Castres, diz- se que duas internas deram muito trabalho a Emilie de Villeneuve. Uma fazia imprudências para prejudicar a própria saúde a fim de voltar para sua família. A outra preocupava-se tanto consigo mesma que queria conversar quase continuamente com a nossa boa Madre. Achando não haver muito tempo 
durante o dia, ia se deitar na cama de Ir. Josephine que ficava perto da de nossa boa Madre. Quando a irmã adormecia, ela se levantava e ficava conversando uma parte da noite com a superiora.

Esta segunda tinha insônia e cansaço ao longo do dia, o que comia the fazia mal e ficava doente. A não adaptação da primeira e as preocupações fizeram a segunda ter que ficar em repouso profundo, como um estado de stress e diziam a não adaptação dela a "vida dura da Congregação".Como Fernanda Siqueira em seus estudos sobre stress em pastores diz, pode contribuir com alguns exemplos:

(...)os problemas de comunicação, conflitos, falta de confiança,que marcam as relações interpessoais no ambiente de trabalho podem se constituir em fonte potencial de stress. As pessoas têm necessidade de aceitação e apoio por parte de colegas, superiores e subordinados, sendo que a falta de suporte social no trabalho faz com que apresentem sintomas psicofisiológicos de stress gerando insatisfação. BAPTISTA (2014, p. 80)

Uma outra história é a de Irmã Gabrielle: 3 irmãs iriam receber o hábito e a Irmã Gabrielle ainda havia de esperar 2 meses. O bispo foi consultado por Emilie e disse que não iria adiantar o recebimento do hábito. Gabrielle teve uma crise de nervos muito forte e só se acalmou depois de 8 dias. Se confessou diariamente e um dos dias houve recusa para confissão e fugiu após a meditação da manhã. Um quadro de stress e ansiedade a continha. Como coloca Neto, Lotufo, Martins (2009) pode uma certa tensão, assim ser considerada como parte natural da vida e, mesmo, como benéfica. Aliás, não é a tensão em si que tem importância, no caso, mas a forma pela qual se reage a ela e nesse caso não foi benéfica.

Uma das saídas que chama a atenção pelos detalhes é a saída da primeira noviça, em que há o diagnóstico que é a depressão, onde diz-se que a primeira noviça caiu doente, com depressão, logo após sua tomada de hábito. O médico, depois de ter constatado a ineficácia dos remédios, achou oportuno que fosse para sua casa se restabelecer. Isso oito dias antes da festa da Imaculada Conceição. A noviça saiu alguns dias depois da festa; não tirou o hábito religioso. Entretanto, na sua família, começou a não se vestir com o hábito religioso completo. Pensava em sair da Congregação pelo pouco gosto que sentia nos exercícios de piedade.

Ficou claro no depoimento a falta de vontade e aborrecimento com as regras cotidianas. Chama a atenção a volta desta mesma noviça após alguns sonhos e uma voz que dizia o que aconteceria com ela caso ela não voltasse à Congregação: a mãe que a reprenderia e se aborreceria. Via também pessoas que não seguiram as normas sofrendo.

No Cristianismo, como cita Paulo Dalgalarrondo (2008), as formas de cura para as doenças desde a ideia da Idade Média é o arrependimento e a penitência. A doença assim pode significar pecado e afastamento de Deus. A primeira noviça representou isso pelos relatos nas memórias: seus medos e seu arrependimento por ter saído da Congregação. 
E o caso da irmã Magdelaine que se mostra interessante pois como está no relato, jovem que veio do Refúgio de Toulouse para dirigir a oficina do Instituto. Parecia ter uma conduta digna de "uma perfeita religiosa" e o fato de ter usado por algumas horas o uniforme de penitente no Refúgio de Toulouse impediu de se tornar religiosa ali. A conduta da irmã era de falar baixo, pedir licença para pequenas coisas, uma perda de linha ou de fazenda lhe causava pesar. Mas várias vezes viram a irmã comer alimentos repugnantes, ir limpar os lugares mais sujos da casa. Mesmo a madre superiora pedindo para Magdelaine falar mais alto ela não obedecia dizendo que era assim. Após seis meses no Instituto e de ser aceita e abreviando seu noviciado Magdelaine mudou de comportamento: Amor próprio, vontade não submissa, tom autoritário, busca de novos empregos, mau humor. Desculpou-se que desde sua profissão via o inferno aberto a seus pés. Pedia o cargo de mestre das internas no internato onde ela era carregada pelas postulantes. Sua cabeça inventava loucuras. Uma vez disse estar tentada a pegar uma faca para se matar como também as irmãs que não lhe agradavam. Deixava transparecer os ressentimentos dormindo onde falava o que sentia. Foi ser professora. Magdelaine fez novas tentativas mais tarde para entrar na comunidade. Dirigiu-se as irmãs de N.S.de Lautrec e essas escreveram para a fundadora Emilie. E esta respondeu os motivos pelos quais a irmã não se encontrava mais na Congregação e só anos mais tarde foi recebida pelas irmãs da Apresentação em Castres.

Nesse caso, o que se considera um transtorno mental nessa situação é o que não é aceitável como conduta para uma freira. As formas que se concebe o inferno no relato está associada a profissão. Antes da mudança de comportamento também ocorriam problemas, mesmo esta sendo uma "perfeita religiosa": a própria anulação de suas vontades e uma auto depreciação. O fato de somente nos sonhos mostrar seus ressentimentos revela a força social que carregava. Havia também uma importância dada ao cargo e esta queria ser mestre e não só encarregada pelas postulantes, o que demonstra também uma influência da hierarquia religiosa para condição pessoal desta freira.

Um outro relato citado é a saída da irmã Agnes que andava triste e com ar preocupado. O tédio da sua vocação que não havia revelado a ninguém. A irmã começava a chorar quando Emilie falava com ela. A vida religiosa se tornara tão pesada para a jovem noviça que depois de seis meses de noviciado ela pediu para voltar para sua família. Mais um caso de que a preparação para ser freira é um momento religioso importante e que pode ser um peso ou um "fervor religioso" em outros.

Marie Boir também foi outro exemplo de entrada e saída tida como uma pessoa "não equilibrada" pelos seguintes fatos: os pais por não serem católicos e a proibirem de ser freira a 
prendiam. Cansados de proibi-la mandaram-na para casa do tio que a maltratava. Esta fugiu e veio até a Congregação. Mais tarde quis ir embora. Isso mostra como as questões familiares e pessoais são elementos relevantes e influentes para que o líder religioso seja psicologicamente saudável e se afirme em sua religião.

Os arquivos gerais da Congregação correspondem a época que vai de dezembro de 1836 a maio de 1844, quando se transferem para outro local - a Casa Mãe. Sua importância é grande pois mostram as primeiras vivências e primeiras formas de organização. Os relatos não são assinados por alguém, mais há indicação que seja irmã Josephine, que participou destes primeiros momentos. O que foi aqui relatado estão nestes arquivos gerais presentes na biblioteca virtual da Congregação da Imaculada Conceição de Castres.

Para associarmos as ideias citadas anteriormente, vamos ao que cita Neto, Lotufo, Martins (2009) sobre as pesquisas de Malony:

\begin{abstract}
Para MALONY (1988, 1992), três são as definições possíveis para saúde mental: negativa (saúde mental definida em termos de ausência de sintomas), normal (saúde mental definida de acordo com critérios estatísticos) e positiva (saúde mental definida através da presença de certas características). Cada uma dessas opções pode ser adequada, desde que explícita. Não é aceitável, entretanto, sempre usar uma definição positiva de saúde mental e concluir que a religião não é funcional, pois é possível que a religião esteja atuando no sentido de evitar, amortecer ou aliviar sintomas do distúrbio emocional o que, na verdade, resultaria numa forte relação entre religião e saúde mental se esta for definida negativamente. Além disso, é possível que a religião contribua para alguém permanecer mais saudável ao ajudá-la a ajustar-se e a se acomodar à realidade em que está vivendo. Haveria, aqui também, uma forte relação entre religião e saúde mental, mas como está sendo definida pela norma. Assim, nos estudos sobre a relação entre saúde mental e religião é importante ficar explícito que tipo de definição de saúde mental está sendo utilizada, além de se usar um conceito de religião multidimensional e válido. NETO, LOTUFO, MARTINS ( 2009, p.122)
\end{abstract}

\title{
Considerações finais
}

Para perceber de que forma a saúde mental e a religião estão relacionadas em especial na experiência da Congregação da Imaculada Conceição de Castres com as noviças que se preparavam juntamente com a sua fundadora Emilie de Villeneuve levamos em conta a variedade do conceito de religião e de saúde mental. São questões que podem ser diferentes dependendo da história do indivíduo, da sua ligação com a sua religião, com as suas motivações pessoais. No caso das Memórias da Congregação nos relatos da entrada e saída de irmãs pode-se perceber que o momento de escolher e reavivar os votos e inserir-se na 
Congregação efetivamente causou tantas questões individuais, dúvidas e até transtornos psicológicos. Alguns deles que foram citados podem ser assim relacionados:

Primeiro, observando o período das experiências relatadas que é de 1836 até 1844 e levando em consideração o período de início da Congregação e sua adaptação tanto para a fundadora como as suas noviças, percebemos a força que a sociedade e a hierarquia religiosa obteve sobre estas freiras. De alguma forma as exigências, cobranças, autorizações, mandos e desmandos dos bispos e padres, o acompanhamento e atendimento das confissões era algo que afetava o cotidiano da Congregação e o psicológico das líderes religiosas. O início e o período de adaptação de uma vida religiosa é uma fase em que encontramos mais transtornos psicológicos? No caso da Congregação da Imaculada Conceição de Castres é algo relevante, considerando as experiências relatadas. Mas é preciso pensar se esta relevância pode ser dada atualmente em diversos contextos e ambientes que a Congregação se insere. Além de levar em conta a experiência de outras Congregações, até mesmo masculinas.

Devemos lembrar também que neste período algumas regras como o uso do hábito pelas irmãs era algo obrigatório, as irmãs faziam menos atividades fora da comunidade do que hoje por conta de mudanças históricas que fizeram parte da Igreja Católica, como o Concílio Vaticano II e que modificaram as formas que estas irmãs lidam com si mesmas e com a sociedade.

Em segundo lugar, um elemento presente e que a Psicologia da Religião pode colaborar na análise é identificar as relações entre psicologia e religião presentes no sentimento da ideia de pecado que a religião professa. A ideia de pecado e a confissão trazem benefícios ou malefícios dependendo do indivíduo e suas formas de compreensão da própria religião e de si mesmo. A necessidade exagerada da confissão presente em um dos relatos, a forma como se reprime sentimentos e o sentimento de culpa por ter que sair da Congregação e por não possuir as características exigidas é algo que pode eliciar nos indivíduos possíveis transtornos psicológicos.

A forma como o sofrimento e abdicação das vontades pessoais é vista pelo indivíduo também traz consequências positivas ou negativas. No caso de quem se sente bem fazendo aquilo que é o mais difícil "com exageros", como uma das freiras que sempre fazia as piores e mais "sujas" das atividades, considera-se algo negativo. Agora, no sentido em que você supera a sua vontade pensando que isso vai afetar beneficamente a si mesmo e o outro pode ser positivo.

Terceiro, seria interessante perceber que questões psicológicas normalmente podem ser encontradas neste primeiro momento de adaptação de noviças. Pensando também nas 
motivações pessoais e a força que a religião exerce sobre elas. Será que haveria necessidade ou formas de perceber estas questões antes de entrar em uma Congregação? Casos como estes citados permanecem atualmente?

O histórico destas noviças, as questões familiares e a opção religiosa dos pais podem influenciar no processo de adaptação destas na Congregação. Não só o trabalho religioso em si e as exigências deste. Se existem contradições entre a religião dos pais e a da freira pode ser que existam questões psicológicas negativas (como é colocado no relato de Marie Boir“um desequilíbrio"), uma contrariedade rebelde que o faça querer seguir um caminho religioso.

Buscamos trazer exemplos em que a Psicologia da Religião contribui, como neste caso, mostrando um ponto importante de intersecção entre o período de adaptação de freiras e como questões psicológicas estão envolvidas. Também trazer mais pesquisas sobre como a religião e a saúde mental estão relacionadas nestes momentos.

\section{Referências}

BAPTISTA, Fernanda Siqueira. Vulnerabilidade ao stress e estratégias de enfrentamento de líderes religiosos cristãos. Dissertação (Mestrado em Psicologia). Universidade Estadual de São Paulo, Bauru, 2014.

NETO, LOTUFO, MARTINS. Francisco, Zenon, José Cássio. Influências da religião sobre a saúde mental. Ed. EZETEC, 2009.

STREVIS, Carlota, AYMA, M.L., HILARION. As Irmãs Azuis: vida da madre Emilie de Villeneuve. Ed. Casa Provincial, São Paulo, 1960.

SILVA, Rogério Rodrigues. Profissão Pastor: Prazer e Sofrimento. Uma análise psicodinâmica do trabalho de líderes religiosos neopentecostais e tradicionais. Dissertação (Mestrado em Psicologia). Universidade de Brasília, 2004.

Weber, Max. Ensaios de sociologia. Organização e introdução de H. G. Gerth e C. Wright Mills. Rio de Janeiro, Zahar Editores, 1963.

Sites:

O Manancial- Memórias da Congregação da Imaculada Conceição de Castres-1836-1844.

Disponível em: https://pt.calameo.com/read/00054864881a21a070964 Acesso dia $31 / 10 / 2018$. 